\title{
ASTILLEROS ESTATALES E INDUSTRIA NAVAL ARGENTINA: TRAYECTORIA RECIENTE Y DESAFÍOS FUTUROS
}

\author{
Cintia Russo \\ Universidad Nacional de Quilmes, Argentina \\ crusso@unq.edu.ar
}

\section{RESUMEN}

Este trabajo aborda el estudio de la trayectoria reciente de la industria naval pesada argentina y los astilleros públicos (Astillero Río Santiago y Talleres Navales Dársena Norte). Nuestra hipótesis implica una fuerte relación entre el Estado regulador, productor, y financiador y la industria naval pesada argentina, en particular los astilleros públicos. Desde un punto de vista conceptual, nuestro objetivo es el de contribuir a un debate más amplio sobre las relaciones entre el Estado y la industrialización. Desde un punto de vista empírico, explicamos a través de este vínculo el desempeño de un sector industrial. Las consecuencias de las políticas ortodoxas en la industria naval pesada argentina han afectado sistemáticamente la actividad, provocando el cierre de los astilleros, y la casi desaparición de los proveedores de piezas navales. Los cambios en el curso de la política pública desde el inicio del siglo XXI han creado las condiciones de posibilidad de los astilleros públicos.

Palabras clave: Empresas públicas, Industria naval pesada, Astilleros estatales, Argentina. 


\title{
PUBLIC SHIPYARDS AND ARGENTINE SHIPBUILDING INDUSTRY: RECENT HISTORY AND FUTURE CHALLENGES
}

\begin{abstract}
This paper deals with the study of recent developments in the shipbuilding industry in Argentina and public shipyards (Astillero Rio Santiago, and Talleres Navales Dársena Norte). Our hypothesis implies a strong relationship between the State, acting as a regulator, producer, and financier and the shipbuilding industry, in particular the public shipyards. From a conceptual point of view, the aim of this paper is to contribute to a broader debate about the relations between the State and the industrialisation. From an empirical point of view, we identify and explain this link trough the path of an industrial sector. The consequences of the orthodox policy in the shipbuilding industry led to a systematic reduction of the activity, causing the closure of shipyards, and the near disappearance of the naval parts suppliers. Changes in the course of public policy since the beginning of the XXI century created the conditions of possibility of public shipyards.
\end{abstract}

Keywords: State companies, Shipbuilding industry, Public shipyards, Argentina. 
Las expectativas del Estado como instrumento del desarrollo fueron exorcizadas, pero también lo fueron las concepciones utópicas según las cuales el Estado debería limitarse a realizar una suerte de patrullaje social con vistas a la prevención de las violaciones cometidas contra los derechos de propiedad [...]

La consigna de la hora es la reconstrucción del Estado, no su desmantelamiento.

Peter Evans, 1996

\section{INTRODUCCIÓN}

Apertura de la economía, disminución del nivel de intervención estatal y revalorización de los mecanismos de mercado fueron los imperativos de la política económica latinoamericana del último cuarto del siglo XX. En este sentido, el cambio institucional que se presenció entonces en el mundo y en América Latina en particular, tuvo como uno de sus ejes el cuestionamiento de las empresas públicas que iniciaron un período de decadencia cuyo corolario fueron las privatizaciones.

En la Argentina, la desregulación de los mercados, la liberalización del comercio externo, la convertibilidad y las privatizaciones fueron los factores gravitantes de la restructuración de su aparato productivo. Aquello que se denominó la reforma del Estado implicó la privatización acelerada del sector público y de las empresas públicas, fenómeno acompañado de numerosas desprolijidades, muy costosas en términos de pérdida del patrimonio social. Este proceso tiene, como los demás ejes de la política aplicada, efectos "colaterales" sobre la infraestructura básica, la eficiencia y los costos de los servicios y, en consecuencia, en el desempeño global de la economía.

Si aceptamos que en las naciones modernas el Estado cumplió funciones que no cubrían los agentes privados (Polanyi 1989, Gerschenkron 1968), podemos admitir que las empresas públicas tuvieron un papel clave durante la industrialización por sustitución de importaciones (ISI) en América Latina. Desde la segunda posguerra hasta los años ochenta, el Estado además de garantizar las instituciones básicas - propiedad privada y estado de derecho- actuó como distribuidor del ingreso y de los riesgos. Para lograr estos dos últimos objetivos conjuntamente con el crecimiento económico extendió sus competencias estimulando la demanda agregada, la infraestructura, la formación de recursos humanos para la industria y el apoyo al empresariado nacional. A su vez actuó como empresario con la creación de empresas públicas (Reinert 2000). 
En los debates que se abrieron desde los años ochenta acerca del Estado y sus atribuciones e intervención en la economía, se argumentaba la decisiva importancia del mercado de libre competencia para alcanzar el óptimo desempeño de las economías nacionales. Las teorías neoutilitaristas del Estado que se impusieron en ese escenario se amoldaron a las recetas económicas ortodoxas sobre el manejo del ajuste estructural. Por consiguiente, el Estado dejó de considerarse como instrumento del desarrollo para limitarse a la defensa de los derechos de propiedad (Evans 1996: 530). Del Estado se esperaba un riguroso programa de desregulación para consolidar las reformas y garantizar la senda de crecimiento. Este programa adquirió así un papel protagónico dentro de las políticas públicas de corto y largo plazo pero, paradójicamente, denotó profundas asimetrías en torno a las áreas, temas y sectores. Las instituciones del mercado y el poder del Estado eran consideradas como inversamente relacionados; la expansión de las primeras requería de la disminución del segundo (Haggard y Kaufman 1995: 356). Sin embargo, ya desde fines de los años noventa se reconocía un período diferente donde "la consigna de la hora es la reconstrucción del Estado, no su desmantelamiento" (Evans 1996: 556). Se admitía no sólo su importancia en la gestión y administración de la economía, sino también en la eficaz intervención de los mercados y en la consolidación de una estructura institucional perdurable.

Creemos que es posible reabrir el debate acerca de la validez de los cuestionamientos al Estado empresario que caracterizó a la ISI y al Estado minimalista, a través del estudio de la trayectoria de un sector productivo. En estas páginas reflexionamos sobre cómo y en qué medida la intervención del Estado influye en el desempeño de la industria local con la creación de empresas públicas. Bajo esta óptica analizaremos las etapas por las que atravesó la industria naval pesada y los astilleros estatales en la Argentina en los últimos cincuenta años: Astilleros Río Santiago (ARS) y Talleres Dársena Norte (Tandanor), que han determinado en gran medida la trayectoria del sector. La hipótesis de trabajo que proponemos es que la industria naval pesada argentina y los astilleros estatales habrían demostrado a lo largo de su historia una importante dependencia con respecto a la capacidad del Estado para ejercer un papel integral, por lo tanto, en la medida en que el Estado se retire de estas funciones o sólo las ejerza parcialmente pone en cuestión el desempeño del sector.

La política de apertura económica de los años noventa facilitó la incorporación de buques usados causando la desaparición de un gran número de astilleros nacionales, sin embargo, los astilleros estatales, ARS y Tandanor persistieron hasta el presente luego de atravesar períodos de cuasi desmantelamiento, privatización, recuperación y re-estatización. Las 
políticas del último cuarto del siglo XX marcan un punto de inflexión en el presente análisis en el que indagamos acerca de cuáles fueron los factores que influyeron o determinaron la historia de la industria naval pesada y los astilleros estatales así como su proyección futura. Nuestro objetivo es el de volver a pensar, a partir del estudio de un sector productivo, el papel de las empresas públicas en el crecimiento económico. Desde un punto de vista conceptual, nos interesa contribuir a un debate más amplio sobre la relación entre las empresas públicas y el proceso de industrialización. Desde un punto de vista empírico, procuramos identificar y comprender este vínculo estudiando la trayectoria de un sector industrial. Nos planteamos las siguientes interrogantes: ¿cuáles son los factores institucionales y productivos que permiten explicar la creación y expansión de los astilleros estatales y el sector naval pesado argentino? ¿Es posible recrear esas condiciones en el actual contexto? ¿Cuáles son los planteos de los actores sociales del sector frente a los desafíos de la reactivación de la industria naval pesada?

Estructuramos el presente artículo en cuatro partes. En la primera, planteamos la evolución en el último medio siglo de la industria naval pesada argentina a partir de una periodización elaborada desde el punto de vista de la relación entre las políticas públicas y el desempeño de los astilleros; en la siguiente, analizamos la trayectoria de los astilleros estatales, sus desafíos presentes y futuros. En la última parte, presentamos el debate de los actores, liderados por los $\mathrm{AE}$, en torno al presente y futuro del sector. Detrás de este planteo se vislumbra una problemática más amplia sobre las expectativas actuales de las agremiaciones de empresarios y de trabajadores en relación a la intervención del Estado en la economía. Cerramos con algunas reflexiones que nos sugieren estas páginas.

Las fuentes privilegiadas que tomamos para este trabajo son: estadísticas (nacionales, provinciales y de las cámaras empresarias), documentos institucionales, leyes y decretos nacionales y provinciales específicos del sector naval, memorias y balances de ARS (1958-2008) y de la Federación de la Industria Naval Argentina, FINA (1995-2010). Asimismo, hemos realizado entrevistas a informantes clave y utilizado la prensa nacional. Si bien esta última resulta una fuente compleja y polisémica, los periódicos locales se han convertido, para nuestra investigación, en una pieza muy valiosa, ya que sólo en ellos hemos encontrado ciertos datos, referencias, opiniones y percepciones que ninguna otra fuente documental nos ha proporcionado. 


\section{LAS FUNCIONES DEL ESTADO Y LA INDUSTRIA NAVAL PESADA ARGENTINA}

Allí donde la construcción de barcos ha tenido un desarrollo significativo el Estado ha desempeñado un papel central como regulador, productor, demandante y proveedor o articulador de mecanismos de financiamiento, generando las condiciones de posibilidad y viabilidad de la rama naval. Como regulador, el Estado implementa un conjunto de legislaciones que constituyen el tejido normativo de fomento de la actividad; en tanto productor no sólo es propietario y administra astilleros, sino que también se hace cargo de las inversiones destinadas a incrementar su capacidad instalada realizando obras públicas, en especial con la construcción de gradas o diques secos. Como demandante de embarcaciones, el Estado puede sostener el nivel de actividad de los astilleros, y en combinación con otros instrumentos de política actuar atemperando los efectos de los ciclos económicos. Por último, el Estado es proveedor de crédito, instrumento clave para esta actividad, dado que las embarcaciones de la industria naval pesada dependen de una demanda singular, tienen un alto valor unitario y un largo ciclo productivo. Estas características condicionan la asistencia crediticia al sector que no se contempla adecuadamente en los canales financieros privados. A pesar de que los armadores suelen tener financiación propia, en general exigen mecanismos de liquidez inmediata. Es por ello que, en la mayoría de los países, este tipo de garantías es provista por el Estado, dado que durante un período prolongado de construcción el buque no puede constituirse en garantía real.

Los ejemplos históricos de la Unión Europea, los Estados Unidos, Japón, China, Corea, Brasil demostrarían cómo las políticas públicas han sido determinantes en el desarrollo a mediano plazo de la industria naval en el mundo. En el caso de Estados Unidos, la llamada Jones Act obliga a que toda operación de navegación en ríos interiores, lagos y costera en territorio norteamericano sea realizada por empresas norteamericanas, con embarcaciones construidas en el país ${ }^{1}$. Desde las décadas del setenta y del

I La Merchant Marine Act de 1920 (P.L. 66-26I) es una ley federal de los Estados Unidos que regula el comercio en aguas estadounidenses y entre puertos de ese país. La sección 27, más conocida como la Ley Jones, se ocupa del cabotaje y exige que todas las mercancías transportadas por el agua entre puertos de Estados Unidos deben ser realizadas en los buques de pabellón, construido en los Estados Unidos, propiedad de ciudadanos de ese país, y tripulados por ciudadanos y residentes permanentes de Estados Unidos. Dado que el comercio mundial aumentó y la capacidad de financiar empresas en el extranjero aumentó en consecuencia, aparecieron las lagunas existentes en la Ley de estadounidense respecto a que el envío grandes compañías marítimas podrían eludir las regulaciones del trabajo de los Estados Unidos y las leyes y reglamentos comerciales mediante el uso de mano de obra barata, mano de obra impresa, e incluso mano de obra contratada de los países no desarrollados, 
ochenta del siglo XX, Japón, Corea y China han alcanzado una posición preeminente en el mercado internacional con el apoyo de de políticas sectoriales ${ }^{2}$. Brasil ha planificado la expansión de su industria naval pesada con una serie de medidas: Ley del Petróleo (1997), el Plan Navega Brasil (2000), y especialmente el Fondo de Marina Mercante que cambió el acceso al crédito para sus armadores y astilleros, cubriendo hasta un $90 \%$ de los montos de la obra, a tasas preferenciales, con plazos de hasta 20 años (Goulard Filho 2011). Por este sendero, Brasil pasó de tener en el año 2000, 1.900 puestos de trabajo en la industria naval pesada -el punto más bajo en su historia-, a 59.000 en 2011 (Sinaval 2011).

En el caso argentino, una iniciativa gubernamental relevante fue el Decreto Ley N. ${ }^{\circ}$ 6.677/1963, que estableció lo siguiente:

Créase [la Marina Mercante] con la finalidad de promover, desarrollar y ejecutar una política naviera nacional acorde con la política general económica y de defensa nacional. La existencia de la Marina Mercante nacional es acorde con las necesidades del comercio exterior e interior del país Considerando: [...] que el tonelaje marítimo como de cabotaje requiere la necesidad de reposición de su material anticuado, cuya sustitución por buques aptos u modernos [...] debe ser facilitada por el Estado por medio de un adecuado estímulo [...] Es imprescindible contar con una industria naval que facilite rápidas reparaciones y que disponga de adecuados talleres, diques y astilleros navales.

Decreto Ley N. 6.677/1963, de la Marina Mercante.

Desde mediados de los ańos cincuenta, podemos identificar tres períodos en la evolución de los astilleros estatales y de la industria naval pesada argentina: el primero comprende desde los años cincuenta hasta los años ochenta; el segundo abarca toda la década del noventa; y el último comienza en los 2000 y llega hasta el presente.

La primera etapa se caracterizó por un sostenido crecimiento, basado en inversión en equipos y modernización tecnológica con una intensa

así como construir los buques que utilicen mano de obra similar, lo que reduce los costos, mientras que la captura de esa rentabilidad diferencial a costa de los marineros y constructores navales de Estados Unidos. En consecuencia, el propósito de la ley es apoyar a la industria marítima estadounidense. Véase http://congressionalresearch. com/RS2 I 566/document.php?study=The+Jones+Act+An+Overview [30-07-20 I 2].

2 Según las estadísticas del Lloyds Statistics, en 2009 delas nuevas órdenes de construcción de barcos en el mundo, Corea representaba el 26,2\%, Japón el 26, I, China el 44,9 y Brasil el o, I. Véase http://Shipbuilding_Statistics_Sep2009.pdf\&ei=D8 5 LULOeE ZSK8QS8joHQCQ\&usg=AFQjCNFlw_oLqbN9ajK7_GATIbM4bHJGig [0 5-0520I2]. 
participación del Estado. El marco regulatorio de la ISI tuvo una traducción específica para la industria naval pesada argentina que favoreció la articulación de las necesidades del sector -como veremos en estas páginas- por medio de regulaciones y subsidios a la construcción naval. Como productor, el Estado creó astilleros de construcción y reparación de barcos que constituyeron el motor de la actividad naval pesada. Entre los más importantes destacamos: ARS y Fábricas Navales del Estado (AFNE), fundado en 1953 es el astillero líder en la construcción de barcos de gran porte, Talleres Dársena Norte (Tandanor) y Taller de Reparaciones Navales (Tarena) creados en los ańos setenta para la reparación de barcos.

En su función de demandante, el Estado consolidó las empresas públicas que fueron los principales armadores de los astilleros argentinos tanto públicos como privados. Estas empresas y organismos fueron: Armada Argentina, Yacimientos Petrolíferos Fiscales (YPF), Yacimientos Carboníferos Fiscales (YCF), Empresa Flota Fluvial del Estado Argentino (EFFEA), Flota Mercante del Estado y Flota de Navegación de Ultramar (FANU). A partir de la fusión de estas dos últimas se creó, en 1960, la Empresa Líneas Marítimas Argentinas (ELMA) en el marco de la Ley N. ${ }^{\circ}$ 15761/1960 del gobierno nacional. Este evento fue un hito clave para la industria naval pesada argentina: la fecha de la firma del Decreto N. ${ }^{\circ} 7.992$, el 12 de septiembre de 1961, se convirtió en el día de la industria naval argentina. Conocido como Plan Esteverena ${ }^{3}$, el decreto preveía un plan de renovación y expansión de la flota mercante en dos momentos: primero, se adquirirían buques en el exterior, pero en el segundo se encargarían buques exclusivamente a astilleros nacionales. Este fue el impulso decisivo para la industria constructora y reparadora de buques.

Como parte del marco regulatorio de carácter proteccionista, se sancionó en 1969 la Ley N. ${ }^{\circ} 18.250$ de Reserva de Cargas, que establecía que las importaciones oficiales y privadas, financiadas o beneficiadas por cualquier organismo del sistema estatal, debían ser transportadas en buques de bandera argentina. En consecuencia, la marina mercante argentina se beneficiaba de un régimen de reserva de cargas que le aseguraba su participación en los fletes de comercio exterior. Para los años ochenta, ELMA era el principal armador del país, con una flota que representaba aproximadamente el 25\% de la marina mercante nacional; le seguía YPF, con un poco más del 15\%, liderando el sector de fletes petroleros (CEP 2005).

Ahora bien, dada la naturaleza de los bienes que fabrica, la industria naval pesada se apoya en dos pilares: facilidades en el acceso al crédito y mano de obra especializada. Por tratarse de un artefacto que no se produce

3 Por el contraalmirante Esteverena, primer Presidente de ELMA. 
en serie, se requiere, por una parte, profesionales, técnicos y obreros especializados, y por otra, financiamiento que permita la construcción y reparación de bienes con un elevado costo unitario y extenso ciclo productivo. Los mecanismos de apoyo financiero mejoraron desde fines de los años cincuenta con la implantación del crédito naval, administrado por el entonces Banco Industrial. Por Decreto Ley N. ${ }^{\circ}$ 6.677, en 1963 se creó el Fondo de la Marina Mercante (FMM), que otorgaba préstamos a los astilleros públicos y privados para la construcción, reparación o modernización de barcos a través de los impuestos sobre el valor de los fletes (alrededor del 12\%). Es decir, el organismo, aportaba financiamiento y subsidios a los astilleros para el activo fijo y a los armadores públicos y privados nacionales o empresas nacionales de capital privado o mixto para la compra y construcción de buques mercantes o artefactos navales con la garantía de una hipoteca sobre el buque, objeto del crédito (FIDE 1981).

El otro factor determinante para el desempeño de la industria fue el desarrollo de las capacidades técnicas, concepto que incluye el conocimiento y las habilidades necesarias para adquirir, usar, adaptar, mejorar y crear tecnología (Gutti 2009). ARS, Tandanor, Alianza, Astarsa, Arsenal Naval de Puerto Belgrano y el de Zárate tenían escuelas de formación de las cuales se nutría el resto del sector naval y en general la industria metalmecánica. En consonancia con esta evolución, en 1959 comenzó el dictado del curso de ingeniería naval en la Universidad Tecnológica Nacional, y diez años más tarde, para 1969, en el Instituto Tecnológico de Buenos Aires. En la Facultad de Ingeniería de la Universidad de Buenos Aires se creó, en la primera mitad de los ańos sesenta, la carrera de ingeniería naval a partir de un curso de posgrado. Se construyó en aquel momento el Canal de Experiencias de Arquitectura Naval Edmundo Manera, único laboratorio de pruebas en el país y tercero en magnitud en la región donde se formaron numerosas generaciones de ingenieros navales (J. C. Pietranera, comunicación personal, 25 de julio de 2010). El desarrollo de la ingeniería de diseño local estaba asentado, hasta los mediados de los setenta, en los estudios técnicos liderados por ARS-AFNE.

En los astilleros se capacitaba y formaba al personal en diversos oficios, lo cual generó un efecto derrame positivo hacia el resto del tejido industrial por el aporte de recursos humanos altamente calificados. La sinergia de este esfuerzo de formación y las características generales del complejo naval permitieron a los astilleros nacionales, en esta fase, enfrentar los desafíos tecnológicos de la producción y reparación de barcos.

El impulso que se venía dando tuvo un drástico cambio con la llegada del gobierno de Carlos Saúl Menem (1989-1999), siendo reflejo de ello los 
Considerando: que la actual situación de crisis de la Marina Mercante nacional ha derivado en una solicitud de cese de bandera de buques argentinos [...], y [que] la principal causa de la crisis es la falta de competitividad de los buques argentinos por razones derivadas de sus costos de operación [...] la medida propuesta traerá un beneficio inmediato tanto a la economía nacional, como a los actores armatorial y del comercio exterior [...]

Decreto N. ${ }^{\circ} 1.772 / 1991$

En la segunda etapa, que comprende toda la década del noventa, el entusiasmo con que se aplicó el ajuste estructural ortodoxo en la Argentina llevó a la desarticulación sistemática de la actividad naval pesada. Por consiguiente, se redujeron las embarcaciones y artefactos navales fabricados en el país y se registró una neta destrucción de empleo en el sector. En este contexto, la apertura económica determinó una reorientación de la demanda local hacia la importación de embarcaciones, tendencia que se acentuó notablemente a lo largo de la década.

En este período se desarmó el andamiaje legal existente que sostenía, en gran medida, a la industria naval pesada. La norma que inició este sendero fue el Decreto 1.772/1991, que dispuso el cese provisorio de bandera para los buques y artefactos navales, a excepción de los destinados a la pesca, y permitió la inscripción de los armadores en otros registros. De ello se derivó una amplia utilización de las banderas de conveniencia, favoreciendo la explotación de los buques y flexibilizando tributos, regímenes laborales y controles. Como consecuencia directa de la aplicación de este decreto, las embarcaciones extranjeras gozaban del derecho de ser consideradas como de bandera nacional. A su vez, se derogó la Ley de Reserva de Carga para Armadores Argentinos de 1969, argumentando que "la administración pública no debe disponer de medidas que interfieran en la libre oferta y demanda ni que obstaculicen el incremento de la oferta de servicios y transporte" (Decreto N. ${ }^{\circ}$ 2.284/1991). Algo semejante ocurre con el Decreto N. ${ }^{\circ} 1.493 / 1992$, a partir del cual se creó un registro de buques extranjeros, permitiendo el arrendamiento a casco desnudo (charteo) para todo tipo de actividades por un plazo de tres años. En este contrato el locador posee la tenencia del buque por tiempo determinado, incluyendo el derecho de designar al capitán y a la tripulación. Además, se propició la utilización de barcazas usadas para transitar por la hidrovía ParanáParaguay. En 1997, con el desmantelamiento de ELMA por Decreto N. ${ }^{\circ} 343 / 1997$, se estableció un régimen de anotación de contratos de locación de buques y artefactos navales extranjeros. Desde la sanción de 
este decreto, la marina mercante de bandera argentina, prácticamente, desapareció. La Argentina tenía, en 1981, el 36,4\% del total del mercado de fletes del comercio exterior, en 1990 con 152 buques transportaba una carga de 2.875.000 toneladas. Siete años después, en 1997, se vendieron los últimos 6 buques mercantes que quedaban y desapareció ELMA. Para el ańo 2006 sólo el 0,9\% de los fletes del comercio exterior eran nacionales (UTN 2008: 17).

Luego de treinta ańos de existencia se disolvió por Decreto N. ${ }^{\circ}$ 2.687/1993 el FMM, principal fuente de respaldo financiero para la construcción naval. Éste fue uno de los factores determinantes que llevó al cese de actividades de algunos astilleros, tanto estatales como privados. Como resultado del desmembramiento de la marina mercante, de las empresas públicas (YPF, YCF, etc.) y del FMM, el Estado argentino perdió peso como armador y, por lo tanto, como potencial demandante del sector naval. La disolución del FMM es el momento clave que inicia la decadencia de la industria naval pesada.

En suma, el deterioro de la industria naval se tradujo, finalmente, en déficits en la formación de los recursos humanos. "Hoy faltan supervisores, ingenieros y técnicos navales, caldereros, oxigenistas, soldadores, carpinteros de ribera, mecánicos y electricistas navales" (J. C. Casarico, comunicación personal, 15 de julio 2008). En efecto, se descontinuaron las carreras de ingeniería naval en algunas universidades y disminuyeron los ingresantes, cerraron escuelas de aprendices y técnicos y se redujo el ritmo de recambio de nuevos operarios. El balance de este período en términos de recursos humanos es de pérdida neta de mano de obra calificada.

Tras la crisis de 2001, se dio un giro en las políticas económicas, pasando desde una orientación neoliberal a otra que recuperó el rol protagónico del Estado. Muestra de ello es el Decreto $N^{\circ} 1.010 / 2004$, que en sus considerando planteó lo siguiente:

Considerando [...] que las actividades de la industria naval son fundamentales para el desarrollo económico nacional [...] el esquema legal de las normas vigentes produce un desequilibrio entre los diferentes actores de la actividad impidiendo a armadores contar con herramientas legales que les permitan alcanzar razonables grados de competitividad y a los astilleros nacionales desarrollar adecuadamente su capacidad productiva.

Decreto N. ${ }^{\circ} 1.010 / 2004$

En la pos-convertibilidad, el cambio de precios relativos y la devaluación generaron, en principio, factores objetivos de estímulo a la producción 
local. Pero las políticas ejercidas desde 2003 abrirían otras perspectivas al sector manufacturero en general y a lo que aún quedaba del complejo de la industria naval pesada (astilleros, armadores, proveedores, sector portuario).

Los principales astilleros que componen la industria naval pesada en este tercer período, son según información de la Asociación Bonaerense de la Industria Naval (ABIN) y la Federación de la Industria Naval Argentina (FINA): los astilleros estatales, Astilleros Río Santiago (ARS, 1953), Complejo Industrial Naval Argentino (CINAR, constituido por Tandanor, Tarena y ex Domecq García, 2008), y los astilleros privados nacionales, Astilleros Corrientes (1958), Tecnao (1978), Sistemas Portuarios Integrados S.A., SPISA (1976), Astilleros Coserena (1980), Astilleros F. Contessi (1949), Mestrina (1960), Astilleros Patagónicos Integrados (API, 2004), SPI-ALNAVI (2009), Astillero Punta Alvear (2009). Cabe señalar que de este conjunto la mayor parte fuer fundada entre los años cincuenta y ochenta y sólo tres astilleros fueron creados a partir de 2003. Por su parte, los dos astilleros estatales (ARS y CINAR), orientados principalmente a la construcción y reparación de buques en el segmento de transporte de carga, concentran actualmente el 86\% del empleo (FINA 2003). El resto de los astilleros se destinan la construcción y reparación de embarcaciones a la pesca y barcazas fluviales ${ }^{4}$.

En definitiva, en la etapa que se abrió en 2003 con la aplicación de políticas destinadas a revertir las tendencias más regresivas del período anterior comienza a reactivarse el mercado interno y la producción local. Consecuentemente, las medidas adoptadas en los últimos años para el sector naval han neutralizado, en parte, los efectos del ajuste estructural ortodoxo de los ańos noventa. Tal es el ejemplo del Decreto N. ${ }^{\circ} 1.010 / 2004$ por el cual se deroga parte de la normativa anterior, con el objetivo de brindar las bases, necesarias para incrementar sustancialmente la oferta de los armadores argentinos, reduciendo sus costos operativos y permitiéndoles alcanzar los niveles de competencia que el mercado demanda. Asimismo, se establece, entre otros puntos, el tratamiento de bandera nacional a los buques y artefactos navales de bandera extranjera arrendados a casco desnudo bajo el régimen de importación temporaria por armadores argentinos, con excepción de aquellos para los que la industria naval cuenta con capacidad de producción (pesqueros, embarcaciones para recreación y deporte, transporte de pasajeros o de carga inferior a las 5.000 toneladas, barcazas, remolcadores y dragas, entre otros). Incluso, este decreto plantea sólo la importación de aquellos insumos, partes, piezas y/o componentes

4 Tecnao y Astilleros Corrientes se orientan a transporte de pasajeros y transporte de cargas, respectivamente. 
que no son producidos en el Mercosur.

Con la Resolución N. ${ }^{\circ} 78 / 2006$ del Ministerio de Economía y Producción, se limitó la importación de buques usados y en la misma dirección se aplicaron reducciones impositivas y arancelarias al derecho de importación extrazona (Resolución N. ${ }^{\circ} 356 / 04$, Secretaría de Industria, Comercio y de la Pequeña y Mediana Empresa). Si bien la sanción del decreto y de las resoluciones entre 2004 y 2006 reflejan la voluntad de restablecer una política industrial, este instrumento legal resultará insuficiente para reactivar el sector naval pesado.

En cuanto al financiamiento sectorial se implementaron dos instrumentos: el Nación Leasing y el Leasing Naval PyME. El primero era un acuerdo entre el Banco de la Nación Argentina y el Ministerio de Planificación Federal, Inversión Pública y Servicios de la Nación, por el cual se buscó apoyar la construcción de buques en astilleros argentinos. El segundo, el Leasing Naval PyME se orientó al financiamiento de las operaciones de leasing de uso comercial para micro, pequeñas y medianas empresas. Cabe destacar que el Programa Más y Mejor Trabajo del Ministerio de Trabajo, Empleo y Seguridad Social subsidia el costo de la capacitación de personal en el sector.

Puesto que la recuperación de una industria de bienes de capital como la industria naval pesada constituye un fenómeno de largo plazo, resulta, en cierta medida, poco probable si no se articula con el resto del aparato productivo, el acceso al crédito y la creación de instituciones para la formación de recursos humanos. Efectivamente, los astilleros estatales como centros neurálgicos de la industria naval pesada lideran los reclamos actuales de los actores del sector, acerca de la insuficiencia de la política industrial específica.

\section{LOS ASTILLEROS DEL ESTADO: UNA TRAYECTORIA CENTENARIA}

\section{REPARACIÓN DE BARCOS: TANDANOR}

Considerando: que esta empresa se convirtió posteriormente en propietaria de un importante establecimiento industrial, con capacidades operativas que la distinguieron en el contexto internacional y perteneció al Estado Nacional hasta su posterior privatización[...] Revócase [...] el Decreto N.o 2.281/1991, declarándoselos nulos, de nulidad absoluta e insanable e irregulares [...] por los vicios consignados en los considerandos del presente decreto, y todos los actos dictados en su consecuencia, por sufrir de 
iguales nulidades.

Los Talleres Nacionales de Marina se instalaron en 1879 en el varadero sobre el río Luján y en 1898 fueron trasladados a la Dársena Norte en el puerto de Buenos Aires. Para comienzos del siglo XX ya se reparaban en sus diques numerosas embarcaciones, lo cual permite reconocer una cierta capacidad técnica.

Cuando se creó la flota mercante estatal, en 1942, el astillero de Dársena Norte, rebautizado en 1922 Arsenal Naval de Buenos Aires (ANBA), reparó y puso en servicio los buques extranjeros que formaban parte de dicha flota. El Arsenal Naval se convirtió entonces en una empresa dirigida por la Armada Argentina y la Administración General de Puertos, bajo el sistema legal de una sociedad anónima con mayoría de capital estatal. El astillero heredó los dos diques secos de la Administración General de Puertos, la infraestructura de la Armada y la capacidad operativa de la mano de obra. En 1970 el ANBA se transformó en Talleres Navales Dársena Norte (Tandanor).

Para responder al incremento de la demanda de reparaciones en los años setenta, Tandanor amplió sus instalaciones e incorporó al astillero estatal Taller de Reparaciones Navales (Tarena). Allí se construyó, en 1978, el sistema de elevador de buques, Syncrolift, a partir de un acuerdo con la empresa americana Pearlson Engineering.

Tandanor fue objeto del primer ensayo privatizador de la administración Menem. En 1991, por la Resolución N. ${ }^{\circ} 931$ del Ministerio de Defensa, se adjudicó la venta del $90 \%$ de su paquete accionario, y por el Decreto N. ${ }^{\circ}$ 2.281/1991 se autorizó al Ministerio a suscribir el contrato de venta y el llamado de licitación. Con más de un siglo de actividad estatal, en 1992 el astillero fue adquirido por Inversora Dársena Norte (Indarsa). Ante la imposibilidad de completar el total de la operación, pocos años después, en 1999, el grupo se presentó en convocatoria y, en ese mismo año la justicia federal declaró su quiebra (Ministerio de Defensa 2007). La empresa funcionó, hasta 2007, gerenciada por sus trabajadores con un interventor judicial.

Desde 2005 se debatieron en el Congreso los proyectos de ley de traspaso de Tandanor a la órbita pública y la creación de una nueva sociedad del Estado. A pesar del consenso general sobre su recuperación para el patrimonio estatal, existía un punto conflictivo en el debate: el desembolso económico del propio Estado para comprar la quiebra de la concesionaria Indarsa. Finalmente, se firmó el Decreto N. ${ }^{\circ}$ 315/2007, que permitió la 
re-estatización del astillero Tandanor.

Se creó, en el año 2008, un polo naval de construcción y reparación de buques, dependiente del Ministerio de Defensa: el Complejo Industrial Naval Argentino (CINAR) que integra los astilleros Tandanor y el "Almirante Storni" -ex Domecq García- de la Armada Argentina. El CINAR, ubicado en el canal sur sobre el estuario del río de la Plata, en la actualidad es el único acceso a la hidrovía de los ríos Paraguay, Paraná y La Plata, sobre los que se encuentran los puertos aptos para operaciones con buques oceánicos. La importancia estratégica de este polo naval se asienta no sólo en el hecho de que Buenos Aires es puerto terminal en el Cono Sur, sino también en las dimensiones del complejo, que permiten la reparación de buques de gran magnitud.

Actualmente, CINAR desarrolla sus actividades en la Planta de Dársenas al Este, dentro de la zona portuaria de Buenos Aires con una superficie propia de 21 hectáreas donde se encuentra el Syncrolift. Ésta es la pieza clave de la competitividad del polo naval y uno de los pocos elevadores sincrónicos de Latinoamérica. Se trata de una plataforma que permite separar el mecanismo de elevación del lugar de operación, facilitando la reparación de varios buques simultáneamente (N. Mospán, comunicación personal, 5 de marzo 2012).

El CINAR, con muy baja capacidad ociosa, puede realizar reparaciones de mayor complejidad (como el rompehielos Almitrante Irízar y el submarino San Juan). En diez años entre 1991 y 2011 se repararon un total de 1.350 unidades navales de las cuales más del $70 \%$ corresponde a unidades de bandera extranjera y sólo en el año 2007 se repararon casi 3.000 toneladas de embarcaciones nuevas 5 . El incremento de la demanda de servicios del CINAR desde su recuperación demostraría que se ha logrado una ecuación competitiva donde se potencian la ubicación física, las instalaciones y equipamientos y la mano de obra calificada. La suma de estos componentes le permite al CINAR competir en el mercado internacional de servicios de reparación naval: con tiempo, calidad y costos competitivos (N. Mospán, comunicación personal, 5 de marzo de 2012).

Ahora bien, complejo naval enfrenta la necesidad de ampliación y modernización de las capacidades instaladas y la formación de recursos humanos. A fines de los años noventa, la edad promedio de los trabajadores de Tandanor era de 57 ańos, una década más tarde, con un total de 540 trabajadores directos ese promedio descendió a 37. Sin embargo, debido a las nuevas obras la dirección empresaria señala la falta "de personal

5 Véase http://www.tandanor.com.ar/espanol/noticias/o3Acciones/Acciones.htm [ [ oO3-2OII]. 
suficiente [...] y de ingenieros con experiencia en construcciones navales que nos permita atender la actividad normal del astillero [...]" (Osuna 2010).

\section{La Construcción de barcos: Astilleros Río Santiago}

Créase con el carácter de empresa de Estado la entidad denominada "Astilleros Río Santiago y Fábricas Navales" (AFNE) que tendrá a su cargo la dirección, coordinación y el contralor de las tareas de naturaleza industrial y comercial que el Estado cumpla por el intermedio del Ministerio de Marina.

Decreto N. ${ }^{\circ} 10.627 / 1953$

El Astillero Río Santiago ha sido una de las piezas clave que permitió la articulación entre la industria naval pesada y el complejo militar industrial. El contexto histórico de creación del astillero fue el mismo en el que se consideró la necesidad de abastecimiento externo de armamentos y material para el funcionamiento del ejército y la marina. En esta época, se intentó un autoabastecimiento parcial que respondió a la dinámica internacional e interamericana, especialmente movida por consideraciones bélicas y geopolíticas. Los talleres generales de la base naval de la Armada, fueron el embrión del astillero estatal. En 1933, la Armada Argentina decidió fabricar por primera vez unidades navales hasta aquel momento importadas, por lo cual se proyectó la construcción de un astillero que independizara al país de la importación.

El astillero, ubicado a orillas del río Santiago, en el partido de Ensenada al sur de la región metropolitana fue fundado el 15 de Junio de 1953 (Decreto N. ${ }^{\circ}$ 10.627) como Astilleros y Fábricas Navales del Estado (AFNE, integrada por Astillero Río Santiago, ARS, y la Fábrica Naval de Explosivos, FANAZUL). AFNE tenía la misión de dirigir, coordinar y controlar las actividades industriales y comerciales relativas a la industria naval, para las necesidades de la marina de guerra y de la marina mercante. En 1970, AFNE se convirtió en una Sociedad Anónima de capital estatal dependiente del Ministerio de Defensa y en 1976 pasó al Comando en Jefe de la Armada hasta 1984, cuando el astillero regresó a la órbita del Ministerio de Defensa.

ARS, astillero integrado con tendencia a la autosuficiencia, en los años sesenta y setenta realizó significativas inversiones en equipo, infraestructura y capacitación permanente de la mano de obra que le aseguraron su protagonismo en la industria naval pesada argentina en las décadas sucesivas. En los ańos setenta, ARS producía motores para buques con licencia de Sulzer y Fiat, que salían con las marcas ARS-SULZER y ARS- 
FIAT, motores diesel, material ferroviario (locotractoras, boguíes y cruces de rieles), turbinas para centrales termoeléctricas de gran potencia, hasta componentes para centrales nucleares (Russo y Versino 2010).

Los recursos humanos, esenciales para el desempeño competitivo del astillero, se formaron por dos vías: en la Escuela de Aprendices de Fábrica, hoy Escuela Técnica privada de la fábrica Astillero Río Santiago, creada el 30 de junio de 1953 con el objetivo de preparar técnicos para la Industria Naval. Por otra parte, el adiestramiento tradicional y permanente del obrero se daba en el taller como aprendiz bajo la guía de maestros en su oficio.

A partir de la reestructuración de los años noventa, ARS atravesó períodos de casi desmantelamiento hasta que, finalmente, sobrevivió como astillero de montaje y reparaciones. Es por ello que, entre fines de los años ochenta y la primera mitad de los años noventa se lee insistentemente en sus memorias y balances que la infraestructura se encontraba subutilizada por la falta de nuevas órdenes de trabajo y de programas de construcciones navales, lo cual afectaba el plan de acción de la empresa (G. Benedetti, comunicación personal, 26 de abril de 2008, ARS 1966-2008). Se anunciaba así el comienzo de una larga decadencia.

Transferido en 1993 de la jurisdicción nacional a la Provincia de Buenos Aires mediante el Decreto Nacional N. ${ }^{\circ}$ 1.787/1993, ARS evitó el fantasma del cierre aunque no el de la privatización, ya que entre los objetivos del Decreto de Transferencia se explicitaba mantener dicho objetivo final. Este proceso se dio casi conjuntamente con la creación de la Zona Franca en el puerto de La Plata, por lo cual el astillero perdió más de la mitad de su predio (comedor, vestuario, talleres de locotractora, fundición, usina eléctrica y parte de la playa de estiva de chapa naval). Lo singular de esta situación es que no fue la empresa la que decidió instalarse en la Zona Franca, como generalmente ocurre, sino que la Zona Franca se estableció en el predio que pertenecía al astillero desde décadas atrás.

El 12 de septiembre de 2008, día de la industria naval argentina, el entonces Presidente de ARS, Lelio González Eliçabe, entregó a la firma alemana Wilhelm Finance Inc. la construcción número 75 de su historia, el buque granelero Casanna ${ }^{6}$. Casi el $90 \%$ de ese total de embarcaciones fueron fabricadas entre 1953 y 1988 y sólo el resto se realizó entre 1989 y 2008 (Russo y Versino 2010). Desde el punto de vista de las órdenes de trabajo, comprobamos que durante medio siglo los armadores públicos nacionales representan casi el $70 \%$ de la demanda (sólo la Armada Argentina y ELMA concentraron el 50\%) (ARS, 1966-2008).

6 www.astillero.gob.ar [27-04-2012]. 
Históricamente, el mercado interno ha sido el destino privilegiado de la producción de ARS, mientras que el internacional sólo representó menos del $10 \%$. Sin embargo, cabe destacar que este destino ha cobrado un peso definitivo a partir del 2003 con el inicio de la recuperación de la empresa (ARS, 2003-2008). En el momento de su provincialización, la empresa tenía 1.153 obreros y empleados, 1.845 cinco años después y a partir del 2004 comenzó aumentar su número, para alcanzar en 2011 los 2.870 trabajadores (G. Benedetti, comentario personal, 26 de abril de 2008).

En el contexto de la ISI, con todo su andamiaje institucional, económico financiero y de formación de recursos humanos, ARS fabricó más de un barco por ańo. Recién a comienzos del siglo XXI, desde 2003-2004 la industria naval pesada argentina y el astillero de Enseñada parecen transitar un camino signado por la recuperación de algunas líneas de construcción de barcos, pero a un nivel productivo muy inferior con respecto a aquel primer período (J. C. Casarico, comunicación personal, 5 de julio de 2008, R. Podetti, comunicación personal, 24 de noviembre de 2011, N. Mospán, comunicación personal, 5 marzo de 2012).

La supervivencia de los AP, ARS y Tandanor, ante la desregulación y reestructuración de los años noventa no tiene una interpretación evidente. En principio, mantuvieron abiertas sus puertas por la resistencia organizada de los trabajadores a la privatización, articulada con movimientos sociales y regionales sustentados en un ideario nacionalista e industrialista opuesto a la política del Gobierno nacional. En este sentido se puede agregar que también la estrategia de la dirección de los astilleros estatales se alineó con los intereses antiprivatistas de los sindicatos y de la propia Armada. Por otra parte, en el caso de ARS, el Gobierno de la provincia de Buenos Aires se enfrentó con los objetivos del gobierno nacional, e intervino en el conflicto desplegado en una región neurálgica para la gobernabilidad de la provincia y creó la Zona Franca de La Plata en las instalaciones del astillero. Identificamos otro aspecto de carácter coyuntural: la situación de la construcción naval en el mercado internacional que en los años noventa atravesaba una fase de recesión, deslocalización, concentración y reestructuración productiva lo que explicaría la falta de ofertas de compra sobre todo para el caso del ARS (FINA 2001). Finalmente, los astilleros estatales no atraían a inversores privados del sector naval dado porque combinaban una ecuación desalentadora: "atraso tecnológico con un sindicato fuerte” (I. Mahler, comunicación personal, 25 de junio de 2010). La precoz privatización de Tandanor sólo se puede comprender si se tiene en cuenta que los terrenos del astillero eran objeto de una intensa reestructuración urbana e Indarsa, la empresa que ganó la licitación, estaba interesada en inversiones inmobiliarias. 


\section{LOS ASTILLEROS DEL ESTADO: UN DEBATE RECIENTE}

La normativa de los años noventa minó las bases del aparato productivo argentino signando un período de más de diez años de casi destrucción de la rama naval. De esta manera lo consideró la Federación de la Industria Naval Argentina (FINA) en los debates sobre "Propuestas y principios sostenidos para una legislación sobre el transporte por agua y carga de pasajeros", con que encaró la fase de recuperación del sector naval en base a la previsión de un cambio sustancial en las políticas de Estado (FINA 2003) ${ }^{7}$. FINA tuvo en cuenta para su diagnóstico ciertas ventajas competitivas con las que contaba aún la industria naval, esto es: la existencia de una capacidad instalada disponible, la presencia de los astilleros estatales y, fundamentalmente, la trayectoria y cultura de fabricación naval representado en las potencialidades y calidad técnicas de los recursos humanos. No obstante el peso de estos factores en la actual fase de reactivación, los astilleros estatales y la industria naval pesada argentina exigen a los decisores de política medidas específicas en materia de fomento industrial. Estos reclamos, liderados por la dirigencia empresarial y sindical de los astilleros estatales, expresan claramente las deficiencias y necesidades de largo plazo del sector. Estos planteos apuntan en primer lugar a la derogación de las regulaciones de los ańos noventa y al restablecimiento de un esquema normativo e institucional que, de algún modo, recree el de la ISI.

A la salida de la crisis de la convertibilidad, el diagnóstico que tuvo mayor consenso entre constructores y reparadores navales estatales, armadores, cámaras empresarias y sindicatos identificaba la principal causa de la debacle de la industria naval en el marco normativo que facilitaba la importación de embarcaciones desalentando la compra de unidades por parte de los armadores nacionales. Proponen, a partir de esta perspectiva, una serie de instrumentos y acciones tendientes a modificar la legislación de marina mercante e industria naval, exigir una política explícita de crédito e hipoteca naval, fortalecer la formación de recursos humanos, modernizar la infraestructura de transporte y mejorar la navegabilidad de la hidrovía. Pero por sobre todo, para recuperar la industria naval pesada a los niveles de sus "años gloriosos" (entre los años sesenta y ochenta) exigen la articulación de estas medidas. Si bien el Decreto N. ${ }^{\circ} 1.010$ sancionado en 2004 traduce la voluntad política manifiesta del Gobierno nacional para recuperar la industria naval pesada, "un decreto no tiene la fuerza de la ley”, sostiene el ingeniero Raúl Podetti de FINA (R. Podetti, comunicación

7 FINA está constituida por nueve entidades asociadas, agrupadas en seis cámaras en categoría de activas que son: ATNA, CACEL, UCN, CINA Mar del Plata, CINA, Cámara de Talleres Navales y actividades portuarias de Punta Alta, y tres entidades en categoría de adherentes, ARS, CAPINAVAL, AAIN (Memorias, FINA, 2006). 
personal, 24 de noviembre de 2011). Por lo tanto es necesario establecer un nuevo encuadre normativo que legisle para el sistema en su conjunto: transporte por agua, infraestructura de puertos y, en definitiva, que incluya a las empresas nacionales constructoras de buques.

Por cierto, estas proposiciones abarcan un amplio abanico que implica una política con visión de largo plazo orientada a sostener la competitividad del sector. En efecto, desde 2004 se fue consolidando la construcción de un consenso entre los miembros de las cámaras empresarias y sindicatos liderado por los astilleros estatales, fundamentalmente el ARS. Este proceso concluyó con la constitución de la Mesa Nacional de Concertación de la Industria Naval Argentina y la elaboración de un documento que sintetiza este consenso: "Bases para un Plan Estratégico para el Desarrollo y el Crecimiento de la Industria Naval Argentina” (Estigarribia 2012) ${ }^{8}$. En el acuerdo entre armadores, empresarios y dirigentes gremiales se contemplan aspectos básicos pendientes en la agenda del Estado, a saber:

1. El fomento de la fabricación y reparación nacional de todo tipo de embarcaciones (incluyendo las de recreo y turismo).

2. La promoción, la reconversión y la modernización tecnológica de los astilleros y talleres navales, considerando la complementariedad y/o asociatividad en la inversión con el Estado.

\section{La revaluación de los aspectos impositivos y arancelarios que atentan} contra el desarrollo de la industria?.

\section{La consideración de las asimetrías con Brasil.}

8 Entre los principales participantes de esta iniciativa del sector podemos mencionar a: ARS; Tandanor; FINA; Cámara de la Industria Naval Argentina, CINA; Unión de Constructores Navales(UCN); Cámara de Constructores de Embarcaciones Livianas (CACEL); Cámara de Proveedores de la Industria Naval (CAPINAVAL); Estudios de Ingeniería Naval, Asociación Argentina de Ingeniería Naval (AAIN); Consejo Profesional de Ingeniería Naval (CAPIN); Asociación de Talleres Navales Argentinos (ATNA); Cámara de la Industria Naval de Mar del Plata (CINA Mar del Plata); Cámara de la Industria Naval de Punta Alta; Asociación Bonaerense de la Industria naval (ABIN); Asociación Patagónica de Industriales Navales (APIN); Talleres de reparación de embarcaciones; Cámaras de armadores navales, navieros de ultramar, cabotaje y pesqueros; Armada Argentina, Prefectura Naval Argentina y otros estatales; Sindicato Argentino de Obreros Navales (SAON); Sindicato Obreros de la Industria Naval (SOIN); Asociación de Trabajadores del Estado (ATE) y Sindicato de Trabajadores de Talleres y Astilleros Navales (SITTAN).

9 Para exportar un buque se debe financiar el 2 I \% del IVA de todos los bienes y servicios que intervienen en una construcción, lo cual implica un monto elevado para que lo cubra un astillero, dado que en ocasiones "puede ser mayor que el capital del astillero" (Pietranera, 25de julio de 2010) 
5. La intervención en proyectos ligados con la producción para la defensa y seguridad en aguas argentinas, interior y mares, trabajando en conjunto con la Armada y la Prefectura Naval Argentina.

6. La formación de recursos humanos tanto de profesionales como de la mano de obra, estimulando el desarrollo de aplicaciones de tecnología de origen nacional con el apoyo de universidades y centros de ingeniería naval. Es por ello que proponen impulsar la educación técnica naval profesional como parte del sistema educativo nacional.

En el marco de este consenso se acuerda sobre las decisiones políticas más urgentes que debería asumir el gobierno de turno, esto es:

\section{La formalización de la Dirección de la Industria Naval.}

2. La creación de una institución financiera orientada al desarrollo que incluya a la industria naval.

3. La dictación de una ley de la industria naval y la marina mercante que dé sustentabilidad y previsibilidad al sector.

En primer lugar, se considera el nombramiento de una autoridad a nivel nacional para coordinar y gestionar los distintos sectores de intereses marítimos y fluviales, en los que la industria naval tenga un papel preponderante, ya que los funcionarios relacionados con el sector están diseminados en diferentes secretarías. Por tanto, impulsan la creación de una subsecretaría de actividades navieras e industria naval, que dependa de la Secretaría de Transporte o, en su defecto, una dirección de la industria naval dentro de la Subsecretaría de Puertos y Vías Navegables.

El financiamiento naval es uno de los elementos que determinan el desempeño de la rama. En este sentido, la eliminación del FMM en 1993 y las dificultades de acceso a líneas de crédito bancarias en los últimos veinte años, obligaron a los astilleros a autofinanciarse o hacerlo a través de sus proveedores. La ausencia de préstamos y subsidios no se refiere sólo a la construcción de embarcaciones (pesadas y livianas) sino que ha llevado a la desinversión crítica en equipamiento e infraestructura. De allí que se considere imperativa la revitalización de los mecanismos de préstamos para incrementar las inversiones y la innovación tecnológica en el sector. Sin embargo, aunque la institución del leasing naval implementado a partir de 2004 ha sido una herramienta valiosa para incentivar la colocación de órdenes de trabajo, se considera que, por sí sola, es inadecuada para los astilleros durante la construcción ya que sólo permite al armador obtener una fuente de financiación una vez concluida la embarcación. Por esta 
razón, todavía existe un importante déficit en la prefinanciación de la obra y el armado coherente de medidas que fortalezcan el crédito naval y permitan la amortización acelerada de los buques construidos en el país ( $R$. Podetti, comunicación personal, 24 de noviembre de 2011).

En el último término se reconoce la necesidad de un marco legal sustentable en el largo plazo, como aquel que existió en los años sesenta y setenta con el fin de consolidar la reconversión de la industria naval. Se propone, efectivamente, una ley única que reúna al armamento y a la industria, mediante incentivos para la renovación de flotas nacionales y la incorporación de buques nuevos para evitar la compra de buques usados. La mesa de concertación plantea en consecuencia que la competencia en el mercado internacional desde el punto de vista arancelario e impositivo debe darse en un esquema comercial de "buque nuevo contra buque nuevo". Por ello, el ingreso de buques de cabotaje nacional y los servicios auxiliares sólo pueden realizarse con buques en calidad de nuevos.

A raíz de estos planteos han tomado estado parlamentario varios anteproyectos de ley de reactivación de la marina mercante nacional y reserva de carga, en los que se establecen objetivos comunes para incentivar y promover las actividades vinculadas con el sector. Se procura, por esta vía, regular la actividad naviera a fin de establecer el dominio de bandera argentina, tanto en el comercio local como en el internacional al mismo tiempo que promover el desarrollo de la industria naval pesada argentina. Más aún, los actores coinciden en que debe respetarse "el principio integrador que considera a la marina mercante y a la industria naval como partes del mismo sistema económico y que, por lo tanto, deben tener un único tratamiento normativo" (Fundamentos del Proyecto de Ley de la Industria Naval 2006).

\section{"EL ESTADO COMO PROBLEMA Y COMO SOLUCIÓN". A MODO DE CONCLUSIÓN}

La economía argentina y las características del Estado han oscilado como en una suerte de péndulo entre la industrialización sustitutiva sostenida en el mercado interno y los ajustes ortodoxos. La imagen de equilibrio que ofrece esta metáfora, como sabemos, es sólo un espejismo. La realidad argentina del último medio siglo ha sido volátil e incierta. El tránsito de políticas proteccionistas a otras de economía abierta en lo comercial y financiero, implicó, en este período, una modificación sustancial de la base productiva.

La dinámica de la industrialización latinoamericana implicó, en el largo plazo, la creación de un tejido productivo, institucional y jurídico 
que constituyó el sustento de la acumulación de un volumen crítico de capital social y la consolidación de una cierta cultura manufacturera. El Estado, actor determinante en este proceso, implementó políticas y creó empresas públicas que caracterizaron la ISI desde la segunda posguerra hasta mediados de los años setenta. Estas políticas estaban sesgadas a favor de la producción estatal en áreas como las telecomunicaciones, energía, transporte, acero, petróleo y petroquímica, carbón, etc. Las empresas creadas por el Estado tuvieron un peso significativo sobre el desarrollo de largo plazo de estas economías y particularmente en la configuración del sector manufacturero, estimulando la adaptación y aplicación de tecnología, capacitando a subcontratistas y proveedores para mejorar sus rutinas de producción y sus procedimientos de control de calidad. Como resultado de estas actividades se generó y difundió conocimiento a los proveedores y contratistas asociados estrechamente con el funcionamiento de las empresas públicas.

De acuerdo al paradigma neoutilitarista, desde la década de 1980, luego del "fracaso" en tanto promotor del desarrollo y el crecimiento, el "Estado era un problema”, por ello debía reducirse a su mínima expresión. La voluntad de establecer este Estado minimalista operó, en la Argentina de los años noventa, adoptándose medidas económicas ortodoxas sobre el manejo del ajuste estructural (Evans 1996): liberalización del comercio, desregulación y privatización de las empresas públicas. Es en este sentido que el Estado empresario dejó de ser un factor influyente de la economía argentina como lo había sido en décadas anteriores. Por un lado, a partir de las privatizaciones, las empresas públicas redujeron su participación en el PIB y, por otro, cedieron su papel de liderazgo en la generación de tecnología y en la formación del capital humano. Estas políticas han sido mecanismos poderosos y no neutrales, con efectos que se reflejarían en el aparato productivo nacional (Katz 2008).

En la industria naval pesada argentina las consecuencias de estas políticas condujeron a una sistemática contracción de la fabricación de buques y artefactos navales, provocando el cierre de un gran número de astilleros, la casi desaparición de la industria naval-partista, un marcado retraso tecnológico y la consecuente pérdida de mano de obra calificada. Las causas directas de esta decadencia fueron, sintéticamente, la desregulación del mercado de transporte internacional de mercaderías, la pérdida de privilegios de las reservas de cargas de los armadores locales, la competencia con los grandes operadores internacionales, la apertura a la importación de buques usados a casco desnudo, la desregulación de la actividad de la marina mercante, la eliminación del FMM, el cierre de algunos astilleros estatales y el sistema de impuestos y aranceles. De esta enumeración 
queremos subrayar, nuevamente, las dos problemáticas determinantes en el desempeńo de la rama: la falta de apoyo financiero y el déficit de recursos humanos. Por ello identificamos el inicio de la decadencia de la industria naval pesada en el país con la eliminación del FMM y la reducción de la demanda del Estado, limitada a la reparación de barcos para la Armada y la Prefectura nacional.

La inversión original que puso en marcha los grandes astilleros fue impulsada por el Estado, sin esta intervención hubieran sido casi imposible sostener un sector cuyo retorno es de largo plazo. ARS se inició en la década de 1950 como un astillero estatal integrado con tendencia a la autosuficiencia, adiestró a sus trabajadores, desarrolló una trama de proveedores en la región con efecto derrame positivo. En Tandanor, astillero de reparaciones que comenzó a fines del siglo XIX, se iniciaron los primeros maestros artesanos de los oficios navales, se proyectó hacia el aparato productivo articulando su actividad con una densa trama de proveedores y subcontratistas. ARS y Tandanor, empresas estatales de larga trayectoria, atravesaron desde los ańos ochenta y noventa la desarticulación productiva, la virtual privatización y re-estatización.

Los cambios en el rumbo de las políticas públicas desde el inicio del siglo XXI generaron las condiciones de posibilidad de la revitalización de los astilleros estatales, por lo cual hoy ARS y CINAR, como pilares de la industria naval pesada argentina, representan casi el $90 \%$ del empleo total del sector. Este cambio de contexto estimula la reconstrucción del tejido más profundo de la industria naval pesada sustentado en la acumulación de capacidades construidas en el largo plazo, como la excelencia y calidad de la mano de obra que aún conserva el oficio. Sin embargo, a pesar de que la voluntad del Gobierno pareciera propiciar el "rescate" de la industria naval pesada resulta insuficiente para garantizar un desempeño competitivo en el mercado internacional. Este proceso exigiría la combinación de cambios a nivel micro, de las funciones productivas, y a nivel macro de la creación de incentivos y políticas industriales sectoriales que persistan y modifiquen en el largo plazo el patrón de especialización.

El origen y trayectoria de los astilleros estatales y la industria naval pesada argentina inspira las expectativas actuales de los actores del sector sobre la acción del Estado. De él se espera que genere las condiciones que fortalezcan un entramado productivo, legal e institucional y que recree, de alguna manera, las políticas que promovieron la industrialización argentina a lo largo de medio siglo, en donde intervinieron las instituciones y la mano visible del Estado. 


\section{REFERENCIAS}

Astilleros Río Santiago (ARS). (1966-2008). Memorias y Balance General. Buenos Aires: Astilleros Río Santiago. . (2010). Manual de Oficios y Tareas según Especialidad de la Carrera de Producción y Mantenimiento. Buenos Aires: ARS.

. (2005). Organigrama de ARS (1996-2005). Documento interno de la empresa.

Azpiazu, D. y Basualdo, E. (2004). Las Privatizaciones en la Argentina. Génesis, Desarrollo y Principales Impactos Estructurales. Buenos Aires: Facultad Latinoamericana de Ciencias Sociales.

Belini, C. (2006). Reestructurando el Estado Industrial: El Caso de la Privatización de la DINIE 1955-1962. Desarrollo Económico 46 (181), 89-116.

Belini, C. y Rougier, M. (2008). El Estado Empresario en la Industria Argentina. Buenos Aires: Manantial.

Bellini, N. (1996). Stato e Industria nelle Economie Contemparanee. Roma: Donselli Editore.

Cáceres Ruíz, J. I. (2003). Política Industrial: El Sector de Construcción Naval en España. Tesis de Doctorado, Universidad Complutense de Madrid, España. Disponible en http://eprints.ucm.es/tesis/19972000/S/2/ S2020701.pdf [20-08-2012].

Calá, C., Mauro, L., Grańa, F. y Borello, J. (2008). La Industria Naval Argentina: Antecedentes, Dinámica Reciente y Situación Actual. Mar del Plata: FCEyS. Disponible en http://nulan.mdp.edu.ar/1099/1/00562. pdf [08-07-2009].

Centro de Estudios para la Producción (CEP). (2005). La Industria Naval en la Argentina. Buenos Aires: Subsecretaría de Desarrollo Productivo de la Secretaría de Industria de la Nación.

. (2005). La industria Naval Pesada en la Argentina. Disponible en http://www.cep.gov.ar/html/industrial.htm [09-11-2011].

. (2006). La industria Naval Liviana en la Argentina. Disponible en http://www.cep.gov.ar/html/industrial.htm [10-11-2011]. 
Coscia, S. (1981). La Industria Naval Pesada. Desarrollo y Perspectivas del Mercado Argentino.. Buenos Aires: Banco Nacional de Desarrollo.

Comín, F., Aceña, P. (Comp.). (1991). Historia de la Empresa Pública en España. Madrid: Espasa Calpe.

Díaz Fuentes, D. (2004). La Empresa Pública en Europa. Madrid: Síntesis

Dosi, G., Freeman, C. y Fabiani, S., (1994). The Process of Economic Development: Introducing Some Stylized Facts and Theories on Technologies, Firms and Institutions. Industrial and Corporate Change, $3(1), 1-45$.

Estigarribia, D. La Mesa Nacional de Concertación de la Industria Naval Argentina. La Nación, 13 de marzo 2012.

Evans, P. (1996). El Estado como Problema y Solución. Desarrollo Económico 140 (35), 529-562.

. (1976). Las Empresas Públicas en la Economía Argentina. Buenos Aires: Consejo Empresario Argentino.

Federación de la Industria Naval Argentina (FINA). (2001). Evolución Reciente de la Industria Naval Argentina. Federación de la Industria Naval Argentina. Buenos Aires: FINA.

. (2003). Memorias. Buenos Aires: FINA.

Frassa, J. (2009). Evitando el Naufragio de la Privatización. El Caso del Astillero Río Santiago en los '90. Tesis de Maestría, Facultad de Ciencias Sociales, Universidad de Buenos Aires, Argentina.

Frassa, J. Russo, C. y Benedetti, G. (2011). Resultados Provisorios de un Relevamiento en el Astillero Rio Santiago. Bernal: Universidad Nacional de Quilmes.

Fundación de Investigación para el Desarrollo (FIDE). (1981). Estudios Especiales: La Industria Naval En La Argentina. Buenos Aires: FIDE.

Gerschenkron, A. (1968). El Atraso Económico en Perspectiva Histórica. Madrid: Alianza Editorial.

Gobierno de la Provincia de Buenos Aires. (2006). Primer Plan Quinquenal del Astillero Río Santiago y bases para la Industria Naval Nacional. Provincia de Buenos Aires: Gobierno de la Provincia de Buenos Aires. 
González Climent, A. (1973). Historia de la Industria Naval Argentina. Ensenada: Imprenta AFNE.

Gutti, P. (2009). Características del Proceso de Absorción Tecnológica de las Empresas con Baja Inversión en I+D: Un Análisis de la Industria Manufacturera Argentina. Tesis de Maestría, Universidad Nacional de General Sarmiento, Argentina.

Haggard, S. y Kaufman, R. (1995). Estado y Reforma Económica: La Iniciación y Consolidación de las Políticas de Mercado. Desarrollo Económico, 139 (35), 355-372.

Instituto Nacional de Estadística y Censo (INDEC). (1989) Censo Nacional Económico 1985. Industria Manufacturera, Resultados Definitivos. Buenos Aires, INDEC.

. (1997). Censo Nacional Económico 1994. Avance de Resultados. Industria Manufacturera. Buenos Aires: INDEC.

Kampetter, W. (1995). Fertilidad Nacional, Estado-Nación y Sistema Económico Mundial. Nueva Sociedad, 137, 84-119.

Katz. J. (1998). Aprendizaje Tecnológico Ayer y Hoy. Revista de la CEPAL, número extraordinario, 63-75.

Katz, J. y Kosacoff, B (1989). El Proceso de Industrialización en la Argentina. Evolución, Retroceso y Perspectivas. Buenos Aires: Centro Editor de América Latina.

Mesa Nacional de Concertación de la Industria Naval Argentina. (2008). Bases para un Plan Estratégico para el Desarrollo y el Crecimiento de la Industria Naval Argentina. Documento interno.

Millward, R. (2006). Private and Public Enterprise in Europe: Energy Telecommunications and Transport, 1830-1990. New York: Cambridge University Press.

Ministerio de Defensa. (2007). Informe sobre Tandanor. Buenos Aires: Presidencia de la Nación.

Osuna, P. (2010). Tandanor Vuelve al Ruego e Incorpora Personal. La Nación, 20 junio 2010. 
Panaia, M, Lesser, R. y Skupch, P. (1973). Estudios sobre los Orígenes del Peronismo. Buenos Aires: Siglo XXI.

Polanyi, K. (1989). La Gran Transformación. Los Orígenes Políticos y Económicos de Nuestro Tiempo. Buenos Aires: La Piqueta.

Rodríguez, J. O. (1981). Industria Naval Pesada. Buenos Aires: Gerencia de Investigaciones Económicas.

Reinert, E. (2000). The Role of the State in Economic Growth. En Toninelli, P. A. (ed.), The Rise and Fall of State-Owned Enterprise in the Western World. Cambridge: Cambridge University Press..

Russo, C. (1998). La Argentina de los 90: Transformaciones Macroeconómicas y Reestructuración Productiva. En Nochteff, H., Azpiazu, D. y Basualdo, E (Ed.), La Economía Argentina a Fin de Siglo: Fragmentación Presente y Desarrollo Ausente. Buenos Aires: EUDEBA.

Russo, C. y Versino, M. (2010). Estado, Tecnología y Territorio: El Desarrollo de Bienes Complejos en Países Periféricos. Revista Estudios Regionales y Mercado de Trabajo, 6, 283-303.

Russo C. y Frassa, J. (2012). Trayectoria Reciente y Perspectivas Futuras de la Industria Naval Pesada Argentina: los Astilleros Estatales. Revista Estudios Regionales y Mercado de Trabajo, 8, 77-98.

Schorr, M. (2004). Industria y nación. Poder Económico, Neoliberalismo y Alternativas de Reindustrialización en la Argentina Contemporánea. Buenos Aires: Ed. Edharsa.

Schvarzer, J. (1996). La Industria que Supimos Conseguir. Una Historia Politico-Social de la Industria Argentina. Buenos Aires: Planeta.

Sindicato Nacional da Indústria da Construção e Reparação Naval. (SINAVAL). (2011). A Indústria da Naval e o Desenvolvimento Brasileiro. Disponible en http://www.sinaval.org.br/docs/IndNavalDesBrasil-2011.pdf [22-08-2012].

Toninelli, P. A. (Ed.). (2000). The Rise and Fall of State-Owned Enterprise in the Western World. Cambridge: Cambridge University Press.

Ugalde, A. (1983). Las Empresas Públicas en la Argentina. Magnitud y Origen. Buenos Aires: CEPAL. 
Unión Industrial Argentina (UIA). (2005). Cadena de Valor de la Industria Naval en la Región Pampeana. Presentación en el 5to Foro Federal de la Industria, Mar del Plata. Disponible en http://www.uia.org.ar/ download.do?id=423 [22-04-2012].

Universidad Tecnológica Nacional (UTN). (2008). Industria Naval Argentina. Disponible en http://www.monografias.com/trabajos-pdf/ industria-naval-argentina/industria-naval-argentina.pdf [08-04-2011].

\section{Leyes y Decretos}

Decreto N. ${ }^{\circ} 10.627 / 1953$, de 15 de junio de 1953, de Astilleros y fábricas navales del Estado.

Ley N. 15.761/1960, de 30 de septiembre de 1960, de Empresa Líneas Marítimas Argentinas.

Decreto N. ${ }^{\circ} 7.992 / 1961$, de 12 de septiembre 196, de. Renovación y ampliación de Empresa Líneas Marítimas Argentina.

Decreto Ley N. ${ }^{\circ}$ 6.677/1963, de 19 de agosto de 1963 del Fondo nacional de la Marina Mercante.

Ley N. ${ }^{\circ}$ 18.250/1960, del 10 de junio de 1969, del Transporte de toda importación con destino al Estado en Buques de Bandera Nacional

Ley N. 20.447/1973, de 22 de mayo 1973, de la Promoción de Marina Mercante Nacional.

Decreto N. ${ }^{\circ} 1.772 / 1991$, de 3 de septiembre de 1991, de la Marina Mercante.

Decreto N. ${ }^{\circ}$ 2.284/1991, de 1 de noviembre 1991, de la esregulación del Comercio Interior de Bienes y Servicios y del Comercio Exterior.

Ley N. ${ }^{\circ}$ 2.404/1991, de 4 de diciembre de 1991, de la Reforma del Estado y Empresas militares y privatizaciones.

Decreto N. ${ }^{\circ} 1.493 / 1992$, de 24 de agosto de 1992, del Registro de Buques y Artefactos Navales Extranjeros.

Decreto Nacional N. ${ }^{\circ} 1.787 / 1993$, de 26 de agosto de 1993, del Contrato de transferencia de AFNE SA a la Provincia de Buenos Aires. 
Decreto Nacional N. ${ }^{\circ}$ 2.687/1993, de 28 de diciembre de 1993, de la Disolución del Fondo de la Marina Mercante.

Decreto Provincial N. ${ }^{\circ}$ 4.538/1993, de 20 de diciembre de 1993, de la Creación del Ente administrativo del Astillero Río Santiago.

Decreto N. ${ }^{\circ} 2.281 / 1991$, de autorización al Ministerio de Defensa a suscribir el contrato de venta de Tandanor y el llamado de licitación.

Decreto N. ${ }^{\circ}$ 343/1997, de 16 de abril de 1997, del Transporte Marítimo Fluvial.

Decreto N. ${ }^{\circ} 315 / 2007$, de 30 de marzo del 2007 del Ministerio de defensa por la recuperación del astillero Tandanor por parte del Estado.

Decreto N. ${ }^{\circ} 1.010 / 2004$, de 6 de agosto de 2004, de la Marina Mercante Nacional.

\section{Resoluciones}

Resolución N. ${ }^{\circ}$ 511/2000, de 29 de junio de 2000, del Ministerio de Economía y obras y servicios públicos de la Nación por la que se regula el Régimen de importación de líneas de producción usadas.

Resolución N. ${ }^{\circ}$ 78/2006, de 23 de febrero de 2006, del Ministerio de Economía y Producción de la Nación por la que se regulan el Régimen de importación de líneas de producción usadas.

Resolución N. ${ }^{\circ}$ 356/2004, de 18 de marzo de 200, de la Secretaría de Industria, Comercio y de la Pequeña y Mediana Empresa por la que se crea el Registro de Astilleros y Talleres Navales.

\section{Proyectos de Ley}

Proyecto de ley de régimen para el transporte por agua, conformación de una flota mercante argentina, registro nacional de buques, 2001.

Proyecto de ley federal de Marina Mercante, 2004.

Proyecto de ley Creación del Fondo para el desarrollo de la industria naval nacional (FODINN), 2004.

Proyecto de ley de actividades navieras y promoción de la industria naval, 2005. 
Fundamentos para el Proyecto de ley de la industria naval, 2006.

\section{Entrevistas}

Gastón Benedetti, contador del área de costos de Astilleros Rio Santiago, entrevistado el 26 de abril 2008.

Juan Carlos Casarico, instructor de la Escuela Técnica de Astilleros Rio Santiago (ETARS) entrevistado el 15 de julio de 2008.

Daniel Yacobits, empleado del área de Administración, Astilleros Rio Santiago, entrevistado el 15 de julio de 2008.

Israel Mahler, empresario industrial, Presidente de la UIA entre 1991 y 1993, entrevistado el 25 de abril, 27 de mayo, 25 de junio de 2010.

Carlos Rosenfeld, técnico naval, proveedor naval, entrevistado el 25 de julio de 2010.

José Carlos Pietranera, ingeniero naval, ex Presidente de Tandanor y Astilleros Rio Santiago, entrevistado el 25 de julio de 2010.

Raúl Podetti, ingeniero naval, miembro directivo de la Federación de la Industria Naval Argentina, entrevistado el 24 noviembre 2011.

Néstor Mospán, ingeniero naval, entrevistado el 5 de marzo 2012.

\section{Páginas web institucionales}

Astilleros Rio Santiago. http://www.astillero.gba.gov.ar [20-10-2012].

Nuestromar. http://www.nuestromar.com.ar [15-05-2012].

Tandanor. http://www.tandanor.com.ar/espanol/noticias/03Acciones/ Acciones.htm [10-10-2012].

Federación de la industria naval argentina. http://www.fina.org.ar/ [0110-2012].

Asociación Bonaerense de la Industria Naval, ABIN. http://www. industrianaval.org.ar/inicio.php. [03-10-2012]. 


\section{Material Audiovisual}

Astilleros Rio Santiago. Historia del Astillero Rio Santiago. [Audiovisual]. Editado por el Departamento de Relaciones Institucionales de Astilleros Rio Santiago, 2008.

Asociación de Trabajadores del Estado (ATE). 80 Aniversario de ATE. Pelear vale la pena. Editado por ATE Ensenada, 2007.

Tandanor. Tareas de reparación del ARA San Juan, Tandanor, 2010. Disponible en: http://www.youtube.com/watch?v=kW2fb8KerxI [0404-2012.]

Recibido: 29-10-2012

Aceptación de la versión final: 20-03-2013 